\title{
Use of Smoked Tobacco but no Information about Non-smoked Tobacco Use
}

National Cancer Institute

\section{Source}

National Cancer Institute. Use of Smoked Tobacco but no Information about Non-

smoked Tobacco Use. NCI Thesaurus. Code C154517.

An indication that it is known that an individual used smoked tobacco products, but it is unknown if they also used smokeless tobacco products. 